\title{
Projeto criativo: Intervenção com alunos e desenvolvimento profissional de
}

\section{professores}

\section{Project criativo: Intervention with students, teacher professional development}

\author{
Ana Margarida Veiga Simão, Janete Silva, Ana Lúcia Agostinho, Joana Marques \\ Faculdade de Psicologia da Universidade de Lisboa
}

\begin{abstract}
Resumo
O Projeto CriaTivo promove competências de autorregulação na escrita que, através do trabalho colaborativo em sala de aula com professores, procura contribuir, simultaneamente, para o desenvolvimento das competências de escrita dos alunos e para o desenvolvimento profissional de professores do $1 .{ }^{\circ}$ Ciclo do Ensino Básico. Serão apresentadas algumas das opções diferenciadoras deste projeto (e.g., recurso à narrativa e ao lúdico) e um conjunto de metodologias e técnicas suportadas pela evidência científica. Serão ainda discutidos os resultados da avaliação do projeto realizada pelos professores, bem como o impacto do trabalho colaborativo na prática pedagógica dos professores.

Palavras-chave: estratégias de autorregulação na escrita, desenvolvimento profissional de professores, trabalho colaborativo.
\end{abstract}

\begin{abstract}
The CriaTivo Project promotes self-regulation skills in writing which, through collaborative work in the classroom with teachers, seeks to simultaneously contribute to the development of students' writing skills and to the professional development of teachers in Primary Education. Some of the differentiating options of this project will be presented (e.g., narrative and playfulness) and a set of methodologies and techniques supported by scientific evidence. The results of the evaluation of the project carried out by the teachers, as well as the impact of the collaborative work on the teachers' pedagogical practice will be discussed.
\end{abstract}

Keywords: self-regulation strategies in writing, professional teacher development, collaborative work.

O mundo atual coloca a todos os cidadãos desafios diversos, fruto de uma realidade em constante mudança. Estes desafios provocam permanentes confrontos com o saber e, no caso dos professores, apelam a um questionamento contínuo do seu papel de docente. O contexto de trabalho, enquanto local de construção do conhecimento profissional dos professores, assume particular importância, pois permite um "vaivém entre uma teoria e uma prática que a interpreta, a desafia, a interroga e, por isso, também a fecunda e faz desenvolver" (Formosinho \& Machado, 2007, p.77).

Considerando esta problemática, o Projeto CriaTivo (Veiga Simão et al., 2017) foi desenhado não só com o objetivo de apoiar o desenvolvimento da competência escrita nos primeiros anos, nuclear para o sucesso académico, pessoal e profissional dos alunos, mas também propõe a colaboração através da estimulação de interações recíprocas entre os professores e o psicólogo da educação. Neste contexto de colaboração, torna-se visível o envolvimento dos professores na partilha de reflexões, no assumir responsabilidades ao longo do projeto, transformando a sua prática naquele momento e contexto.

\section{Escrita Criativa: Trabalho colaborativo em sala de aula}

As competências relacionadas com a escrita assumem-se como fundamentais para o sucesso escolar e social dos indivíduos. Em particular, a escrita criativa requer o uso da linguagem para refletir, explorar e expressar as experiências do escritor de forma única, imaginativa e com sentido. Deste modo, trabalhar a escrita criativa em contexto de sala de aula exige, por parte de quem lidera, a promoção de uma comunicação eficaz das experiências dos alunos, de modo que, no seio do grupo, a exploração das potencialidades deste tipo de escrita aconteça de forma mais produtiva do que em contexto individual (Vass, 2002). Estando claro que a criatividade é um potencial disponível em todos os indivíduos e pode ser desenvolvida intencionalmente, não se devendo a um "dom" que só algumas pessoas possuem, mas sim, a um conjunto de competências que podem ser aprendidas e aperfeiçoadas (Kaufmann, 2002), a intervenção nesta área só faz sentido quando os profissionais da educação trabalham em estreita colaboração. Neste sentido, o modus operandi do Projeto CriaTivo, baseou-se no trabalho de articulação entre os professores titulares de turma e os psicólogos da educação. Consequentemente, este trabalho colaborativo, foi o cenário criado para promover o desenvolvimento profissional dos professores no âmbito das competências de autorregulação na escrita, em contexto real.

Por outro lado e, igualmente importante, foi a possibilidade de se assumir o projeto como conteúdo programático de aprendizagem, bem como verificar no trabalho de sala de aula com os alunos a aplicabilidade direta das estratégias autorregulatórias partilhadas durante as sessões de formação. 


\section{Narrativa: Elemento promotor dos processos autorregulatórios na escrita}

$\mathrm{Na}$ estruturação do projeto, assumiu-se como referencial teórico o construto de autorregulação da aprendizagem (Zimmerman, 2013), promovendo a aprendizagem da escrita de uma forma autónoma e proativa por parte do aluno, onde este mobiliza as suas características pessoais e desenvolve estratégias assertivas para maximizar a aprendizagem (Malpique \& Veiga Simão, 2015). Este construto compreende dimensões (cognitiva/metacognitiva, comportamental, motivacional e contextual) que estão envolvidas nos processos psicológicos implicados nas diversas fases da autorregulação: fase prévia (forethought), fase do controle volitivo (performance/volitional control) e fase de autorreflexão (self-reflection), estando cada uma das fases relacionada de forma recíproca. Para Zimmerman (2013), estas fases cumprem, assim, um ciclo de ação na autorregulação, continuamente aberto a novos desenvolvimentos, com recuos e avanços, sempre diferentes, porque foram enriquecidos pela experiência anterior, pelo contexto em que ocorrem e pelos resultados que se vão alcançando.

Constituindo-se como um desafio, o processo de escrita requer que o escritor saiba balancear dois principais elementos: a imaginação criativa e o conhecimento ou domínio de técnicas de escrita adequadas (Watts, 2007). Assim, no Projeto CriaTivo recorreu-se à narrativa e ao lúdico como elementos centrais na promoção de estratégias de planeamento, monitorização e revisão do processo de escrita. As sessões foram dinamizadas a partir de um imaginário alusivo às fases da autorregulação: o pirata Tivo e a sua arara Cria vivem uma aventura no Arquipélago da Escrita, constituído por três ilhas: a do Vulcão (planeamento), a da Cascata (redação) e a do Farol (revisão). Tendo em conta o racional que suporta este trabalho, os seus objetivos foram: 1) promover a aprendizagem de estratégias autorregulatórias associadas ao processo de escrita; 2) fomentar atitudes motivacionais em relação à escrita; 3) promover a criatividade na composição escrita; 4) fomentar a produção escrita; e 5) promover a qualidade da composição escrita.

\section{Método}

\section{Participantes}

A 1. ${ }^{a}$ edição foi implementada em cinco escolas públicas da região metropolitana de Lisboa, incluindo três escolas inseridas no programa Territórios Educativos de Intervenção Prioritária (TEIP). O projeto foi implementado em 16 turmas e estiveram envolvidos 359 alunos do $3 .^{\circ}$ e $4 .^{\circ}$ ano (7-12 anos), bem como os seus respetivos professores titulares de turma.

A 2. ${ }^{a}$ edição foi igualmente implementada em cinco escolas públicas da região metropolitana de Lisboa, incluindo quatro escolas inseridas no programa TEIP. Abrangeu 15 turmas, sendo uma destas turmas de ensino bilingue (Língua Portuguesa e Língua Gestual Portuguesa), num total de 314 alunos do $3 .^{\circ}$ e $4 .^{\circ}$ ano (7-16 anos) e respetivos professores titulares de turma.

\section{Procedimento}

O projeto organiza-se em 15 sessões, agrupadas em três fases:

Fase 1. Sessão de contacto inicial com os professores para apresentação do projeto, levantamento de expectativas e identificação de dificuldades antecipadas.

Fase 2. Intervenção direta com os alunos em parceria com os professores. Esta fase é composta por 13 sessões com características e objetivos distintos: 1) Sessão inicial: dedicada ao estabelecimento da relação, avaliação inicial e apresentação do projeto aos alunos; 2) Sessão 1 a 11: direcionadas à estimulação da escrita através do ensino explícito de estratégias de autorregulação na escrita (planeamento, redação e revisão) e da promoção da criatividade e qualidade da escrita; 3) Sessão final: destinada à avaliação final, à avaliação do projeto pelos alunos e à finalização do projeto com a descoberta do Tesouro da Escrita.

Fase 3. Workshop final para todos os professores envolvidos no projeto, onde são partilhados e discutidos os resultados da avaliação dos alunos e onde os professores são convidados a avaliar o projeto e a partilhar experiências entre si.

As sessões da Fase 2 possuem uma lógica interna composta por cinco momentos: 1) acolhimento; 2) leitura da narrativa; 3) atividade de escrita; 4) reflexão sobre a atividade; e 5) término da sessão. A leitura da narrativa, a atividade de escrita e a reflexão são os elementos centrais de cada sessão e seguem uma lógica sequencial e cíclica. A leitura da narrativa introduz a atividade de escrita, que conduz a uma reflexão autorregulatória e alimenta a continuidade da narrativa. De referir que estes momentos enunciados separadamente podem decorrer em simultâneo, por exemplo, quando a leitura da narrativa promove a reflexão ou quando as atividades de escrita remetem para o imaginário. Entre sessões, os alunos têm a possibilidade de resolver desafios de escrita em casa, de forma autónoma e voluntária, cuja concretização é registada em gráfico de turma.

Durante esta fase, os professores colaboram com os formadores na dinamização das sessões, tendo um papel mais ativo e autónomo (i.e., sem a intervenção dos formadores) em 3 momentos distintos: 1) Dinamização de uma atividade de escrita entre as Sessões 6 e 7, com documento orientador; 2) Facilitação de um momento de reflexão com a turma, entre as Sessões 9 e 10, sobre o racional teórico das três fases de autorregulação na escrita (i.e., planeamento, redação e revisão); 3) Planeamento e implementação de uma nova sessão orientada para as necessidades específicas de cada turma, envolvendo a construção de um excerto da narrativa do pirata Tivo e da arara Cria.

\section{Metodologias}

Avaliação da eficácia do projeto. Antes e após a intervenção, foi pedido aos alunos para escrever um texto subordinado ao tema "A aventura", num tempo máximo de 30 min. De acordo com o procedimento de implementação, foi fornecido aos alunos uma folha com linhas (para a redação) e uma folha em branco (para o plano), com a instrução de que deveriam escrever o seu 
texto na folha de linhas e que poderiam utilizar a folha branca como lhes parecesse mais útil.

Utilizando uma metodologia de teste-reteste, foi pedido a peritos para escolher o melhor de ambos os textos produzidos pelos alunos, relativamente à qualidade holística e à criatividade da escrita (1. ${ }^{\mathrm{a}}$ edição) e, relativamente a cinco critérios da qualidade da escrita: estrutura, conteúdo, vocabulário, pontuação e originalidade (2. ${ }^{\mathrm{a}}$ edição).

Por outro lado, de forma a avaliar a evolução ao nível da extensão da produção escrita, foi contabilizado o número de palavras e o número de frases dos textos escritos antes e após a intervenção.

A partir da observação da utilização da folha branca, avaliou-se ainda o tipo de estratégias de planeamento demonstrado em ambos os textos: 1) sem evidências de planeamento, 2) ensaio ou rascunho, 3) tentativa de planeamento.

Através do registo dos textos produzidos em sessão (i.e., sessões 1 a 11) e entre sessões (i.e., desafios para casa), avaliou-se frequência da produção escrita ao longo do projeto.

Avaliação das expectativas iniciais dos professores. $\mathrm{Na}$ sessão de contacto inicial com os professores (Fase 1), foi realizada um focus group para avaliar conceções sobre escrita, perceção de obstáculos e sugestões para otimizar o projeto.

Avaliação do projeto pelos professores. No workshop final (Fase 3), foi pedido aos professores para responder ao um questionário de avaliação do projeto, de forma a avaliar o grau em que os objetivos do projeto foram alcançados, a sua perceção da evolução dos alunos, bem como o seu grau de satisfação com o projeto. Após o preenchimento do questionário, os professores participantes foram distribuídos por dois grupos de discussão, com o objetivo de partilharem a sua avaliação geral ao projeto, as experiências ao longo do mesmo, opiniões e sugestões para edições futuras.

\section{Resultados}

\section{Avaliação da eficácia do projeto}

A qualidade e a criatividade da escrita foram avaliadas com base na comparação dos textos produzidos antes e após a implementação do projeto (i.e., metodologia de teste-reteste). Na 1. a edição, na qual esta avaliação se baseou na análise holística dos textos, encontrou-se uma percentagem de melhoria de 55\% tanto ao nível da qualidade como da criatividade da escrita. $\mathrm{Na} 2 .^{\mathrm{a}}$ edição, onde a avaliação teve em conta os cinco critérios já mencionados, verificou-se que $61 \%$ dos alunos melhorou a estrutura da sua escrita, $58 \%$ melhorou o conteúdo, $58 \%$ melhorou o vocabulário, $50 \%$ dos alunos melhorou a pontuação utilizada nos seus trabalhos de escrita e 53\% dos alunos melhorou a criatividade na escrita.

Os resultados relativos à extensão da produção escrita indicam que houve um aumento tanto no número de palavras como no número de frases por texto. $\mathrm{Na} 1 .^{\mathrm{a}}$ edição, 193 alunos (58\%) aumentaram a extensão dos seus textos. Em todas as turmas foram encontrados alunos que aumentaram o número de palavras, sendo que a percentagem de aumento da extensão varia entre
$27 \%$ e $88 \%$ de alunos por turma, assumindo uma média de 55\% (Figura 1). Na 2. ${ }^{\text {a }}$ edição, 111 alunos (57\%) aumentaram a extensão do texto. Em todas as turmas foram encontrados alunos que aumentaram o número de palavras, sendo que a percentagem de melhoria varia entre os $20 \%$ e os $85 \%$ de alunos por turma, assumindo uma média de 53\% (Figura 2).

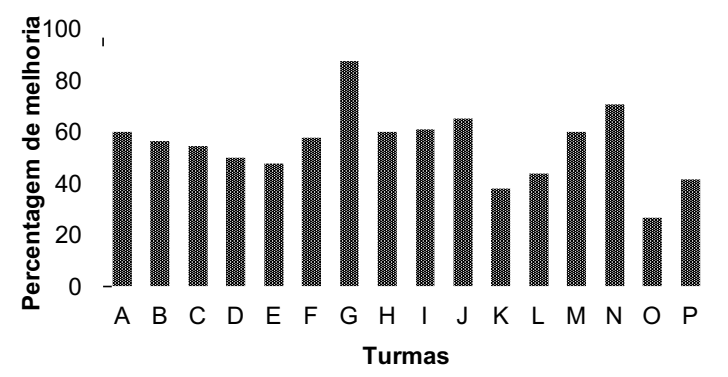

Figura 1. Percentagem de alunos que aumentou o número de palavras do texto ( $1 .^{\mathrm{a}}$ edição).

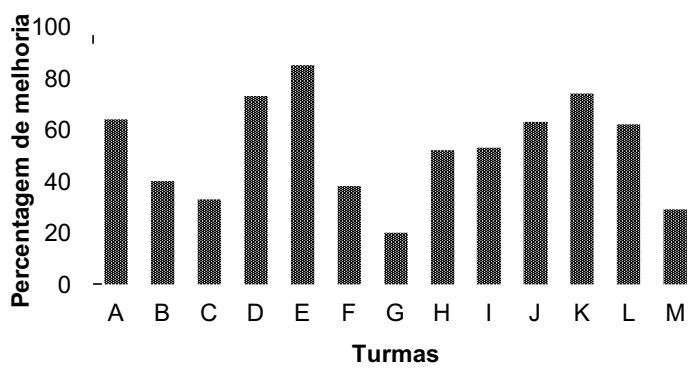

Figura 2. Percentagem de alunos que aumentou o número de palavras do texto (2. ${ }^{\mathrm{a}}$ edição).

No que respeita ao número de frases por texto, verificou-se uma melhoria em 13 turmas, sendo que no final do programa $27 \%$ a $88 \%$ dos alunos por turma aumentou o número de frases, com uma média de 53\%.

Quanto à utilização de estratégias de autorregulação na escrita, foi analisado o planeamento realizado antes e após o programa a partir da observação da utilização das folhas brancas. $\mathrm{Na} 1 .^{\mathrm{a}}$ edição, observou-se que, antes do programa, apenas 1 turma evidenciava intenções de planeamento, sendo a maioria de utilizações da folha branca respeitante a ensaios ou rascunhos. Após a intervenção, o número de utilizações da folha branca aumentou em 14 turmas e, em 13 dessas turmas, verificou-se a prática de um plano prévio à redação. Em suma, o número de ensaios reduziu ligeiramente $(6 \%$ para $5 \%$ ) e o número de planos aumentou (3\% para $20 \%$ ). Na 2. ${ }^{\text {a }}$ edição, observou-se que, antes do programa, apenas 1 turma evidenciava intenções de planeamento ( $22 \%$ dos textos apresentavam plano). Por outro lado, em 2 turmas $13 \%$ das folhas brancas foram utilizadas para ensaio ou rascunho. Após a intervenção, o número de utilizações da folha branca aumentou em 10 turmas, sendo que, em 9 destas turmas verificou-se a prática de um plano prévio à redação e, em 5 destas turmas, a elaboração de um ensaio ou rascunho.

Relativamente à produção escrita, durante 11 sessões de intervenção, verificou-se a produção de 4291 textos 
de forma orientada na $1 .^{\mathrm{a}}$ edição e de 3366 textos na 2. edição. Relativamente aos textos produzidos entre sessões, na 1. a edição foi realizado um total de 666 de forma autónoma e voluntária, tendo o número de desafios produzido por aluno variado entre 0 e $26 . \mathrm{Na} 2$. $^{\mathrm{a}}$ edição, foram produzidos 452 textos de forma autónoma e voluntária, tendo o número de desafios produzido por aluno variado entre 0 e 10 .

\section{Avaliação das expectativas iniciais dos professores}

A Fase 1 do Projeto CriaTivo tinha como objetivo perceber quais os desafios antecipados pelos professores, quais as suas expetativas e como encaravam o papel da escrita nas aprendizagens dos seus alunos. De facto, tanto na $1 .^{a}$ como na 2. ${ }^{a}$ edição os professores foram unânimes em considerar que as competências de escrita eram não só transversais às várias disciplinas, como também fundamentais ao longo da vida do aluno e seriam, nesse contínuo, uma ferramenta que abriria portas à criatividade e liberdade de cada um.

Apesar de na sua maioria acreditarem e encararem este projeto como uma mais-valia para a sua formação e de grande relevância na intervenção com os alunos, alguns desafios e obstáculos foram antecipados pelos professores em ambas as edições. Assim, anteciparam dificuldades como motivar os alunos para as tarefas de escrita, conseguir a sua adesão ao projeto, garantindo a participação ativa de toda a turma. Nesse sentido, para ser possível lidar com esses e outros desafios que fossem sendo colocados, foi importante apresentar propostas de trabalho enquadradas ao nível etário e de desenvolvimento psicológico dos alunos, respeitar as dinâmicas de sala de aula e assumir a possibilidade de ser necessário lidar com constrangimentos vários.

\section{Avaliação do projeto pelos professores}

De forma geral, em ambas as edições os professores envolvidos fizeram um balanço muito positivo, identificando diversos aspetos construtivos do projeto que contribuíram para a sua evolução dos alunos em vários domínios. $\mathrm{Na} 1 .^{\mathrm{a}}$ edição, foram referidas as melhorias no planeamento do texto ("[demonstraram evolução ao nível] da planificação dos textos e de os escrever obedecendo a essa planificação"); melhorias na revisão do texto ("[demonstraram evolução ao nível da] revisão da escrita"; "evolução na correção"); maior criatividade ("[demonstraram] evolução na criatividade na elaboração dos textos); aumento da motivação para escrita ("os alunos estão mais motivados para a escrita"; "mostraram maior vontade de produzirem textos de forma autónoma"); melhoria na organização do texto ("evolução ao nível da organização do texto no exercício da escrita"; "os textos escritos por eles estão mais organizados e estruturados"); maior envolvimento com as tarefas de escrita ("demonstraram evolução ao nível da participação ativa”). $\mathrm{Na} 2$. $^{\mathrm{a}}$ edição, foram identificados e referidos pelos professores aspetos similares e em linha com a 1. a edição. Nesse sentido, referiram melhorias na qualidade da produção escrita ("utilizam diferentes expressões para iniciar os textos"...); aumento da criatividade na expressão escrita ("[demonstraram] evolução na criatividade e na elaboração dos textos"); melhoria no planeamento do texto ("[demonstraram evolução ao nível] da planificação dos textos e de os escrever obedecendo a essa planificação"); maior motivação para escrita ("os alunos estão mais motivados para a escrita"; "mostraram maior vontade de produzirem textos de forma autónoma").

Estes contributos, percecionados pelos professores na 1. ${ }^{\mathrm{a}}$ e na $2 .^{\mathrm{a}}$ edições, sobre as competências de escrita e motivação dos alunos são congruentes com os objetivos propostos. Além disso, quando diretamente questionados, a maioria dos professores considera que os vários objetivos do projeto foram alcançados na totalidade e que as atividades desenvolvidas foram bastante relevantes para este fim.

Na Tabela 1 apresenta-se a opinião dos professores quanto ao alcance de cada um dos objetivos do projeto, relativamente à $1 .^{\mathrm{a}}$ edição.

Tabela 1.

Perceção dos Professores quanto ao alcance dos objetivos do projeto na 1. ${ }^{a}$ Edição.

\begin{tabular}{lccc}
\hline Objetivo & $\begin{array}{c}\text { Contribuiu } \\
\text { moderadamente }\end{array}$ & $\begin{array}{c}\text { Contribuiuu } \\
\text { bastante }\end{array}$ & $\begin{array}{c}\text { Contribuiu } \\
\text { completamente }\end{array}$ \\
\hline $\begin{array}{l}\text { Promover a criatividade da } \\
\text { composição escrita. }\end{array}$ & $7 \%$ & $79 \%$ & $14 \%$ \\
$\begin{array}{l}\text { Fomentar as atitudes } \\
\text { motivacionais para a escrita. }\end{array}$ & - & $50 \%$ & $50 \%$ \\
$\begin{array}{l}\text { Estimular a produção escrita. } \\
\text { Fomentar a qualidade da escrita. }\end{array}$ & - & $79 \%$ & $21 \%$ \\
$\begin{array}{l}\text { Incentivar a utilização de } \\
\begin{array}{l}\text { estratégias de autorregulação da } \\
\text { escrita (planear, redigir e rever). }\end{array}\end{array}$ & - & $71 \%$ & $14 \%$ \\
\hline
\end{tabular}

Os professores referiram que os alunos transferiram e aplicaram determinadas estratégias trabalhadas no projeto para o contexto de sala de aula, nomeadamente as estratégias para o planeamento e revisão dos textos, (i.e., destacaram a utilização das mnemónicas e materiais auxiliares utilizados e disponibilizados ao longo do projeto). Tomemos como exemplos: "Quando escreviam alguns textos na sala de aula recorriam aos cartazes da escrita criativa para elaborarem os seus textos."; "Utilizaram todas as estratégias, mas principalmente o código para a revisão dos textos, que continuam a utilizar no seu dia a dia"; "[utilizaram] as mnemónicas, na escrita de todos os seus textos". Todos os professores mencionaram estar satisfeitos com a execução do projeto na sua turma, sendo que a grande maioria ficou completamente satisfeito.

Desta forma, todos recomendam este projeto a outros colegas, pelos benefícios para os alunos ao nível da escrita e de outras competências pessoais: "Os alunos ficam mais motivados e empenhados para a escrita"; "É uma grande ajuda no estímulo à escrita"; "Promovem a motivação para escrita por parte de todos os alunos, algo difícil de concretizar em sala de aula"; "tem muitas estratégias diferentes a utilizar que permitem aos alunos refletir sobre todo o processo de escrita; "estimula a criatividade dos alunos"; "promove competências diversificadas para além das linguísticas". 
Relativamente à 2. ${ }^{\mathrm{a}}$ edição, apresenta-se na Tabela 2 a opinião dos professores quanto ao alcance de cada um dos objetivos do projeto.

Tabela 2.

Perceção dos Professores quanto ao alcance dos objetivos do projeto na $2 .{ }^{a}$ Edição.

\begin{tabular}{lccc}
\hline Objetivo & $\begin{array}{c}\text { Contribuiu } \\
\text { moderadamente }\end{array}$ & $\begin{array}{c}\text { Contribuiu } \\
\text { bastante }\end{array}$ & $\begin{array}{c}\text { Contribuiu } \\
\text { completamente }\end{array}$ \\
\hline $\begin{array}{l}\text { Promover a criatividade da } \\
\text { composição escrita. }\end{array}$ & - & $35 \%$ & $65 \%$ \\
$\begin{array}{l}\text { Fomentar as atitudes } \\
\text { motivacionais para a escrita. }\end{array}$ & $7 \%$ & $21 \%$ & $72 \%$ \\
$\begin{array}{l}\text { Estimular a produção escrita. } \\
\text { Fomentar a qualidade da escrita. }\end{array}$ & $7 \%$ & $28 \%$ & $65 \%$ \\
$\begin{array}{l}\text { Incentivar a utilização de } \\
\text { estratégias de autorregulação da } \\
\text { escrita (planear, redigir e rever). }\end{array}$ & - & $50 \%$ & $43 \%$ \\
\hline
\end{tabular}

Os professores referem que continuaram a utilizar as estratégias introduzidas pelo projeto: ("utilizámos as estratégias do CriaTivo para ajudar numa atividade proposta pela Biblioteca."; "Aprendi muitas estratégias que eu posso usar em aula, adorei."; "utilizei a metodologia do planeamento, redação e revisão para as fichas de avaliação"; "Utilizámos a estratégia da chuva de ideias para planear um poema"; "Eles já planeavam e reviam mas mais formal e isto foi mais lúdico, fez-me repensar, pensar de forma diferente").

Tal como na $1 .^{a}$ edição, todos os professores envolvidos na $2 .^{\text {a }}$ edição, mencionaram estar satisfeitos com a execução do projeto na sua turma, sendo que a grande maioria ficou completamente satisfeito. Desta forma, todos recomendam este projeto a outas turmas, sobretudo, pelos benefícios para os alunos ao nível das competências de escrita ("Nota-se evolução nos textos"; "melhoraram ainda a pontuação e ortografia"; " [evolução ao nível de] produção escrita com maior conteúdo e textos mais longos"), motivação para a escrita ("os alunos estão mais envolvidos"; "vários alunos que não queriam escrever e que atualmente aumentaram a sua extensão e produção escrita"; "a motivação dos alunos é extraordinária, eles acreditam que existiam aquelas ilhas.") e pela promoção da criatividade ("Noto que os alunos estão melhores, mais criativos, os textos melhoraram"). Destacam ainda outros aspetos proporcionados pelo projeto como a oportunidade de refletir sobre a escrita ("é um projeto muito interessante eu leva os alunos a refletiram sobre aquilo que escreveram"; "promove reflexões constantes sobre aspetos importantes para o desenvolvimento desta competência [a escrita]"; [evolução ao nível de] espírito crítico quanto à produção escrita"), promover a literacia ("Melhorou também a leitura dos alunos"; " é um projeto que motiva os alunos também para a leitura") e de ajudar no desenvolvimento de competências pessoais ("a interajuda entre os alunos").

\section{Considerações finais}

O projeto propõe um caminho para atingir uma das metas fundamentais para o desenvolvimento da competência escrita do aluno: canalizar a atenção de todos - alunos, professores, psicólogos - para a necessidade de ensinar, aprender, e aprender a ensinar estratégias autorregulatórias associadas ao processo de escrita. Evidencia também a potencialidade de parcerias entre a universidade, a escola e a autarquia na promoção de oportunidades de desenvolvimento profissional de professores. A colaboração entre os psicólogos educacionais e os professores propiciou o seu desenvolvimento profissional através de interações recíprocas em contexto de sala de aula.

\section{Referências}

Formosinho, J., \& Machado, J. (2007). Nova profissionalidade e diferenciação docente. In M. A. Flores \& I. C. Viana (Eds.), Profissionalismo docente em transição: As identidades dos professores em tempos de mudança (pp. 71-82). Braga: Universidade do Minho.

Kaufmann, J. (2002). Narrative and paradigmatic thinking styles in creative writing and journalism students. Creative Education Foundation, 36(3). http://dx.doi.org/10.1002/j.2162-6057.2002.tb01064.x

Malpique, A.A. \& Veiga Simão, A.M. (2015). Assessing self-regulated strategies for school writing: Cross-cultural validation of a triadic measure. Journal of Psychoeducational Assessment, 33(2), 141-153. http://dx.doi.org/10.1177/0734282914547873

Vass, E. (2002). Friendship and collaborative creative writing in the primary classroom. Journal of Computer Assisted Learning, 18(1), 102-110. http://dx.doi.org/ 10.1046/j.0266-4909.2001.00216.x

Veiga Simão, A.M., Agostinho, A.L., Silva, J., Marques, J., Silva, R.L., Cabaço, S.C., \& Malpique, A. (2017). CriaTivo: Promoção de estratégias de autorregulação na escrita. Lisboa: Faculdade de Psicologia da Universidade de Lisboa e Câmara Municipal de Lisboa.

Watts, J. (2007). Putting author voices in the classroom: A strategy for writing teachers. Virginia English Bulletin, 57(2), 20-31.

Zimmerman, B. (2013). From cognitive modeling to self-regulation: A social cognitive career path. Educational Psychologist, 48(3), 135-147. http://dx.doi.org/10.1080/00461520.2013.794676

\section{Agradecimentos}

Agradecemos à Câmara Municipal de Lisboa o financiamento deste projeto no âmbito do Orçamento Participativo e ao Grupo de Psicologia da Educação e da Orientação do CICPSI da Faculdade de Psicologia da Universidade de Lisboa. Este projeto insere-se no Programa de Estudos da Aprendizagem Autorregulada (PEAAR) http://www.peo.psicologia.ulisboa.pt. 